\title{
Personality predicts prostate cancer treatment decision- making difficulty and satisfaction
}

\author{
Heather Orom 1,2*, Louis A. Penner', Brady T. West ${ }^{3}$, Tracy M. Downs ${ }^{4}$, Walter Rayford ${ }^{5}$ and \\ Willie Underwood' \\ 'Barbara Ann Karmanos Cancer Institue, Wayne State University, Detroit, MI, USA \\ ${ }^{2}$ Institute of Gerontology, Wayne State University, Detroit, MI, USA \\ ${ }^{3}$ Center for Statistical Consultation and Research, University of Michigan, Ann Arbor, MI, USA \\ ${ }^{4}$ San Diego Medical Center, University of California, San Diego, CA, USA \\ ${ }^{5}$ University of Tennessee, Memphis, TN, USA
}

* Correspondence to: University at Buffalo, Department of Health Behavior, School of Public Health and Health

Professions, 304 Kimball Tower, 3435 Main St., Buffalo, NY 14214-8028, USA. E-mail: horom@buffalo.edu

\begin{abstract}
Objective: Prostate cancer (PCa) patients often must decide between several treatment modalities considered equally efficacious, but associated with different benefits and side-effects. For some, the decision-making process can be difficult, but little is known about patient characteristics and cognitive processes that might influence the difficulty of such decisions. This study investigated the roles of dispositional optimism and self-efficacy in PCa treatment decision-making difficulty and satisfaction.

Methods: One hundred and twenty-five patients with clinically localized PCa completed a mail-in paper-and-pencil survey after they had made their treatment decision, but prior to treatment.

Results: After adjusting for covariates, optimism and treatment decision-making self-efficacy were associated with less difficulty and greater satisfaction with the treatment decision-making process. Effects of optimism on difficulty and satisfaction were partially mediated by selfefficacy for making the treatment decision.

Conclusions: Men with PCa and who are low in optimism may be at greater risk for treatment decision-making difficulty and lack of treatment decision-making satisfaction, in part, because they have lower confidence in their ability to make the decision compared with those who are more optimistic. As self-efficacy perceptions are modifiable, consideration should be given to including self-efficacy enhancing components as part of PCa treatment decisionmaking interventions.
\end{abstract}

Copyright (C) 2008 John Wiley \& Sons, Ltd.

Keywords: prostate cancer; treatment decision-making; optimism; self-efficacy; cancer; oncology
Revised: 8 March 2008

Accepted: 27 March 2008

\section{Introduction}

Prostate cancer $(\mathrm{PCa})$ is the most prevalent noncutaneous malignancy in American men[1]. It is estimated that 186320 men will be diagnosed with, and 28660 will die from $\mathrm{PCa}$ in 2008[1]. About $91 \%$ of cases of $\mathrm{PCa}$ are diagnosed when the cancer is still confined to the prostate (clinically localized disease) [1]. The most common treatments for clinically localized PCa are surgery (radical prostatectomy), external beam radiation, implantation of radioactive seeds in the prostate (brachytherapy), and watchful waiting (watching and waiting for cancer progression) [2]. Radical prostatectomy, external beam radiation, and brachytherapy are currently considered equally effective at curing $\mathrm{PCa}$ [3]. Owing to the risk of serious side-effects associated with all forms of definitive treatment, watchful waiting is regarded as appropriate for some men, especially if they are at relatively low risk of dying from their disease because they have low-risk disease (Gleason score $\leqslant 6$, PSA $\leqslant 10$, and cT1c/cT2a), and are older ( $>70$ years of age), or have serious co-morbid disease $[4,5,6]$. Active patient involvement in the treatment decision is generally considered desirable as (1) PCa treatment is an example of 'preferencesensitive care'; that is, there are typically two or more appropriate treatment options available and (2) PCa treatments involve trade-offs between sideeffects and benefits [6-9].

Deciding between cancer treatment options can be stressful [10]. The absence of a single standard of care for $\mathrm{PCa}$ and the threat of quality of lifereducing side-effects (e.g. urinary, bowel, and erectile dysfunction) could increase the complexity 
and potential difficulty of deciding between treatment options. Gwede et al. reported that nearly half of $\mathrm{PCa}$ patients reported experiencing difficulty $(49 \%)$, and, or distress $(45 \%)$ during the treatment decision-making process [11]. Furthermore, treatment decision-making difficulties may have significant long-term negative consequences. Research with breast cancer patients indicates that difficulties and low satisfaction with the cancer treatment decision are associated with decisional regret and worse mental health in survivorship [12,13].

Dissatisfaction and difficulty with the decisionmaking process are part of the overall burden of $\mathrm{PCa}$, and efforts should be made to understand the determinants of treatment decision-making difficulty, identify at-risk patients, and provide effective decisional support to those who are likely to benefit from such support. Personality may be one determinant of how much difficulty patients experience during the treatment decision-making process. Personality includes coherent patterns in an individual's psychological functioning $[14,15]$. In his Knowledge and Appraisal Personality Architecture framework, Cervone proposes that a key process underlying these emergent personality patterns is activation of enduring beliefs, and their influence on appraisals, the process of gauging the significance of features of the environment for one's well-being, and one's ability to cope with potential threats [14]. Empirical evidence supports this model $[16,17]$. Applying this framework to cancer treatment decision-making, we would expect patients to be influenced by the beliefs that they bring to the decision, their appraisals of threats posed by the cancer and the treatment itself, and their perceptions of their ability to meet the decision-making challenge (i.e. self-efficacy).

Dispositional optimism/pessimism, defined as a generalized tendency to expect either positive or negative outcomes in important domains of life, is one example of a coherent set of enduring beliefs about one's relationship with the world [18]. There is ample empirical evidence that whether they are generally optimistic or pessimistic influences patients' well-being, distress, and engaging in physical and psychosocial health behaviors both during and after treatment for cancer [19-22]. Evidence indicates that optimism also predicts how cancer patients cope with treatment decision-making. More optimistic breast cancer patients were found to engage in more planning than patients who were less optimistic, and Wong et al. found that PCa patients who were more optimistic wanted more PCa-related information [23,24]. Steginga found that, in $\mathrm{PCa}$ patients, greater optimism was associated with less decisional and general PCa uncertainty prior to, as well as 2 and 12 months post-treatment, in part, due to more optimistic patients appraising their cancer as less threatening to significant aspects of their lives [25].

There may be multiple pathways through which optimism/pessimism (hereafter simply referred to as optimism) influences coping with adverse circumstances. Results of a recent meta-analysis suggest that one reason that optimistic patients may adjust better to adversity is that they engage more actively and effectively in the coping process [25]. For example, Carver and colleagues found that breast cancer patients who were more optimistic responded to having cancer with more acceptance, less denial, and less behavioral disengagement than patients who were less optimistic. Use of these coping responses accounted, in part, for optimists' lower levels of distress compared with more pessimistic patients [18].

Optimists' ability to engage more fully and effectively in coping or meeting an important challenge, as well as their tendency to appraise the challenge as less threatening may be, in part, due to having higher confidence in their ability to succeed at these challenges compared with people who are less optimistic. Self-efficacy, or perceptions of one's ability to perform a given challenging behavior is a robust predictor of success [26,27]. When engaging in challenging tasks, people who are more self-efficacious experience less anxiety, adopt more challenging goals, persist longer in the face of failure, and adopt more thorough and systematic approaches to solving problems [26,27]. Although there has been little research examining the role of decision-making self-efficacy in patients' cancer treatment decision-making, research on complex decision-making in other settings, such as managers making decision in organizational settings, suggests that loss of confidence in one's ability results in less efficient use of analytic strategies, setting lower decisional goals and lower performance (i.e. worse decisions) $[28,29]$.

\section{Research aims and hypotheses}

The present research addresses a need to understand who is at increased risk for difficult and potentially distressing PCa treatment decisionmaking experiences and to identify modifiable psychological processes that influence satisfaction and difficulty with the process. We examined the roles of optimism and self-efficacy in PCa treatment decision-making difficulty and satisfaction. It was hypothesized that patients who were more optimistic would be more satisfied and experience less difficulty with the decision-making process, and that these effects would be partially mediated by their self-efficacy for making the treatment decision. We tested these hypotheses while controlling for a number of covariates. We first controlled for the degree of importance patients gave to sideeffects when making the decision. Patients who give 
high importance to side-effects when making their decision may find the decision more difficult because they perceive the risk of side-effects associated with treatment as highly threatening or they feel more conflicted about the trade-offs between various treatment options. We also controlled for demographic characteristics and level of agreement between preferred and perceived levels of decisional control, demonstrated in previous research to predict decision-making satisfaction [30].

\section{Method}

\section{Patients}

Two hundred and two patients who had been recently diagnosed with clinically localized PCa were recruited to complete a survey inquiring into factors that influenced their treatment decisionmaking; 159 (78.71\%) returned the survey. They comprised a convenience sample of consecutively eligible men identified by the consulting physician as meeting inclusion and exclusion criteria: (1) biopsy-confirmed PCa; (2) no previous diagnosis and treatment for clinically localized PCa; (3) no signs or symptoms of advanced disease or diagnosis of confirmed metastatic PCa (positive bone scan or CAT scan; (4) were 40 years or older; (5) proficient in English; and (6) self-identified as either non-Hispanic White or non-Hispanic Black (hereafter referred to as 'Black' or 'White'). Of the 159 patients who completed the survey, 34 were excluded from the present analyses because of incomplete data, yielding a final sample of 125 .

\section{Procedure}

Potentially eligible men were approached by a physician (male) or nurse practitioner (female) during a visit to either of the two urology clinics. Interested individuals were administered informed consent procedures. Men who agreed to participate were provided with the survey in person or by mail and instructed to complete and return the survey by mail after they made their treatment decision, but prior to starting/receiving treatment.

\section{Measures}

\section{Independent variables}

Optimism was assessed with the Life Orientation Test-Revised, a 6-item scale (plus 4 filler items) that assesses the extent to which respondents agree with statements such as, 'I hardly ever expect things to go my way', and 'I'm always optimistic about my future' $(\alpha=0.76)$. Participants responded using a 5-point Likert-type response format ran- ging from 'strongly disagree' to 'strongly agree' [31].

Treatment decision-making self-efficacy was assessed with three items $(\alpha=0.85)$ that ask patients to rate their confidence in their ability to, 'ask your doctor(s) questions about your treatment options that concerned you', 'discuss openly with your doctor(s) questions/concerns about developing any side effects after treatment', and 'make the decision about which treatment is best for you after discussing options with your doctor'. Patients rated their confidence on a 3-point response format ranging from 'not at all confident', to 'extremely confident'. Although previous work has used validated measures of self-efficacy for communicating with one's physician [32], interacting with one's physician [33], or generalized self-efficacy [13], none of these measures is designed to specifically measure patient self-efficacy for making a treatment decision.

\section{Dependent variables}

Decision-making satisfaction was measured with the Holmes-Rovner Decision Scale, which consists of seven items that assess agreement with statements regarding satisfaction with various aspects of decision-making (e.g. time to make the decision, level of involvement in decision-making, level of control, coherence of decision with personal values) $(\alpha=0.82)$. Agreement was assessed on a 5-point Likert-type response format ranging from 'strongly disagree' to 'strongly agree' [34].

Decision-making difficulty was assessed with three items $(\alpha=0.87)$. Patients were asked the extent to which they agreed or disagreed with the following: 'Making the decision about the type of treatment to have was stressful', 'it was difficult to make the decision about what treatment to have', and 'knowing the opinions of family members made it more difficult for me to decide what kind of treatment to have'. They rated their agreement with each item on 5-point Likert-type response formats ranging from 'strongly disagree' to 'strongly agree'. Higher scores on the measure represent more difficulty with making the treatment decision.

\section{Covariates}

Influence of side-effects was measured with three items on which patients rated the extent to which possible side-effects of various treatment modalities (interference with one's sex life over the long term, leakage of urine, burning with urination or in rectum) influenced their decision on a 4-point Likert-type response format ranging from 'did not influence decision', to 'greatly influenced decision'. Given that responses to the three items were intercorrelated $(r$ 's $=0.45,0.65,0.69)$ they were combined into a single scale $(\alpha=0.81)$. 
Agreement between preferred and perceived level of decisional control was assessed with a measure adapted from Degner and Sloan [35]. Participants were provided with a total of seven statements corresponding to three different levels of decisional control: passive (e.g. 'My doctor(s) made the decision with little input from me'), collaborative (e.g. 'My doctor(s) and I made the decision together'), and active (e.g. 'I made the treatment decision with little input from my doctor') and asked to select the statement that best represented how: (1) they wanted to make the treatment decision and (2) how the actual treatment decision was made. Responses were coded as either 'matching' if a participant's preferred and perceived levels of decisional control were from the same category, or 'not matching' if a participant's preferred and perceived levels of decisional control were from different categories.

Demographic characteristics (race, marital status, education, income, age) were assessed via patient self-report.

\section{Statistical analyses}

We used standard residual diagnostics to verify normality, linearity, and homoscedasticity of residuals. For descriptive purposes, we conducted a series of unadjusted linear regression analyses to examine bivariate relationships between the predictor variables (optimism, self-efficacy), covariates (influence of side-effects, agreement between perceived and preferred decisional control, demographic variables), and the two outcome variables (decision-making difficulty and satisfaction). Next, we conducted hierarchical multiple linear regressions to examine the relative contributions of the predictor variables and covariates to decisionmaking difficulty and satisfaction. Variables were entered in an a priori order chosen with the intent of examining the unique contribution of optimism and treatment decision-making self-efficacy after accounting for covariates. Categorical predictors (race, marital status, education, income, and agreement between preferred and perceived level of decisional control) were entered as dummy coded variables. Age was not included in the model due to the large number of missing values on the variable (17\% of the study sample).

Finally, we tested whether treatment decisionmaking self-efficacy partially mediated the effects of optimism on decision-making satisfaction and difficulty using a bias-corrected bootstrapping procedure outlined by Preacher and Hayes [36].

\section{Results}

Residual diagnostics revealed no issues with normality, linearity, and homoscedasticity of re-
Table I. Sample demographic characteristics

\begin{tabular}{lc}
\hline \multicolumn{1}{c}{ Characteristic } & $\boldsymbol{n}$ (\% total sample) \\
\hline Race & \\
White & $99(79.2 \%)$ \\
Black & $26(20.8 \%)$ \\
Income & \\
$\leqslant 20000$ & $50(40.0 \%)$ \\
$30000-49$ 000K & $50(40.0 \%)$ \\
$\geqslant 50000$ & $18(14.4 \%)$ \\
Missing & $7(5.6 \%)$ \\
Education & $11(8.8 \%)$ \\
$<$ High school & $35(28.0 \%)$ \\
High school & $59(47.2 \%)$ \\
Some college & $20(16.0 \%)$ \\
College graduate or greater & $77(61.9 \%)$ \\
Marital status & $48(38.4 \%)$ \\
Married/living with someone & $63.0(7.4)$ \\
Unmarried & \\
Mean age (SD) &
\end{tabular}

a Sample $N=125$

$b_{n}=104$.

siduals. Demographic characteristics of the sample are presented in Table 1. For descriptive purposes, Table 2 contains bivariate relationships between the predictor variables, covariates, and decisionmaking difficulty. Also of note, apart from the hypothesized relationship between optimism and self-efficacy, only two sets of predictor variables were related. Optimism varied as a function of level of education $(F(3,121)=6.23, P<0.01)$, with more educated patients tending to be more optimistic than less educated patients. In addition, selfefficacy and agreement between preferred and perceived level of decisional control were positively associated $(r=0.21, \quad P=0.02)$. Finally, mean scores and standard deviations for the continuous predictor variables were: $2.27(1.0)$ out of 4 for importance of side-effects, $3.71(0.61)$ out of 5 for optimism, and $2.67(0.98)$ out of 3 for decisionmaking self-efficacy.

\section{Difficulty with decision-making}

Thirty-one percent of patients reported difficulty with the decision; that is, their mean responses to the difficulty items indicated that they either agreed or strongly agreed with statements about finding the decision process difficult.

Results of the hierarchical multiple regression (Table 3) revealed the relative contributions of the predictors to difficulty with decision making, including the contributions of optimism, and treatment decision-making self-efficacy over and above those predictors of decision-making satisfaction previously identified in the literature (demographic variables and agreement between preferred and experienced decisional control). Demographic characteristics (race, income, education, and marital status) were entered in the first block. This step 
Table 2. Bivariate associations between the predictors and outcome variables

\begin{tabular}{|c|c|c|c|c|}
\hline \multirow{3}{*}{ Predictor variable } & \multicolumn{4}{|c|}{ Outcome variable } \\
\hline & \multicolumn{2}{|c|}{ Decision-making difficulty } & \multicolumn{2}{|c|}{ Decision-making satisfaction } \\
\hline & B & SE & B & SE \\
\hline $\begin{array}{l}\text { Race (Black) })^{* * *} \\
\text { Income } \\
* * *\end{array}$ & 0.28 & 0.22 & -0.09 & 0.11 \\
\hline $30000-49000 \mathrm{~K}$ & -0.19 & 0.20 & 0.03 & 0.10 \\
\hline$>50000$ & -0.23 & 0.27 & $0.28 *$ & 0.14 \\
\hline Missing & 0.11 & 0.40 & 0.07 & 0.20 \\
\hline \multicolumn{5}{|l|}{ Education $* * *$} \\
\hline High school & 0.35 & 0.33 & 0.10 & 0.18 \\
\hline Some college & 0.18 & 0.32 & 0.13 & 0.17 \\
\hline College graduate or greater & -0.31 & 0.36 & 0.22 & 0.19 \\
\hline Marital status (married/living together) ${ }^{* * *}$ & -0.23 & 0.18 & 0.14 & 0.09 \\
\hline Age & -0.02 & 0.01 & 0.00 & 0.01 \\
\hline Influence of side-effects for decision & $0.39^{*}$ & 0.08 & -0.08 & 0.04 \\
\hline Agreement ${ }^{\mathrm{a}}$ & 0.04 & 0.20 & 0.12 & 0.10 \\
\hline Optimism & $-0.5 l^{* *}$ & 0.14 & $0.32 * *$ & 0.07 \\
\hline Treatment decision-making self-efficacy & $-0.79^{* *}$ & 0.20 & $0.55^{* *}$ & 0.09 \\
\hline
\end{tabular}

${ }^{*} P<0.05$

$* * P<0.001$

$* * *$ Referent groups were White, income less than $<\$ 20000$ per year, less than high school education, single.

${ }^{a}$ Agreement between preferred and perceived level of decisional control.

Table 3. Results of hierarchical linear regressions predicting difficulty with decision-making process and satisfaction with decisionmaking process

\begin{tabular}{|c|c|c|c|c|c|c|c|c|}
\hline & \multicolumn{8}{|c|}{ Outcome variable } \\
\hline & \multicolumn{4}{|c|}{ Difficulty with decision-making } & \multicolumn{4}{|c|}{ Satisfaction with decision-making } \\
\hline & $R^{2} \Delta$ & ( $P$ value) & $R^{2}$ & ( $P$ value) & $R^{2} \Delta$ & ( $P$ value) & $R^{2}$ & ( $P$ value) \\
\hline Step I: demographic characteristics & & & 0.07 & 0.33 & & & 0.06 & 0.55 \\
\hline Step 2: agreement & 0.00 & 0.63 & 0.08 & 0.40 & 0.00 & 0.35 & 0.06 & 0.56 \\
\hline Step 3: side effects & 0.16 & $<0.001$ & 0.24 & $<0.001$ & 0.01 & 0.19 & 0.08 & 0.49 \\
\hline Step 4: optimism & 0.07 & $<0.001$ & 0.30 & $<0.001$ & 0.14 & $<0.001$ & 0.22 & $<0.01$ \\
\hline Step 5: self-efficacy & 0.08 & $<0.001$ & 0.38 & $<0.001$ & 0.12 & $<0.001$ & 0.34 & $<0.001$ \\
\hline
\end{tabular}

was not significant $(F(8,116)=1.16, P=0.33)$. Agreement between preferred and perceived level of decisional control was entered into the next block. It did not contribute to the model $\left(R^{2} \Delta=0.00 ; F(1,115)=0.27, P=0.63\right)$. Influence of side-effects was entered next and contributed significantly to the model $\left(R^{2} \Delta=0.16 ; F(1\right.$, $114)=24.18, \quad P<0.001)$. Next, optimism was added to the model, explaining an additional $7 \%$ of the variability in difficulty $\left(R^{2} \Delta=0.07 ; F(1\right.$, $113)=10.89, P<0.001)$. Finally, decision-making self-efficacy accounted for an additional $8 \%$ of the variability in decision-making difficulty $\left(R^{2} \Delta=0.08 ; F(1,112)=13.74, P<0.001\right)$.

Table 4 contains parameter estimates for the final regression model. Controlling for other factors in the model, a unit increase in self-efficacy was associated with a 0.70 point reduction in difficulty on a scale ranging from 1 to $5(P<0.001)$. Optimism also significantly predicted difficulty
$(B=-0.31, P<0.001)$. Regarding the covariates, when all the variables were in the equation, influence of side-effects remained a significant predictor of treatment decision-making difficult $(B=0.37, P<0.005)$, and the regression weights for race and education became significant. Being Black was associated with greater decision-making difficulty $(B=0.41, P<0.05)$. As explained in the Discussion section, this was due to a suppression effect [37].

\section{Mediational analyses}

The addition of treatment decision-making selfefficacy to the model reduced the effect of dispositional optimism on difficulty with decision-making by $32.5 \%$, suggesting that self-efficacy partially mediated the effect of optimism on decisionmaking difficulty. A formal test [36] confirmed that self-efficacy significantly mediated the effect of 
Table 4. Parameter estimates for final linear regression models (all predictors) predicting difficulty with decision-making process and satisfaction with decision-making process

\begin{tabular}{|c|c|c|c|c|}
\hline \multirow[b]{3}{*}{ Predictor variable } & \multicolumn{4}{|c|}{ Outcome variable } \\
\hline & \multicolumn{2}{|c|}{ Difficulty with decision-making } & \multicolumn{2}{|c|}{ Satisfaction with decision-making } \\
\hline & Final model B & SE & Final model $B$ & SE \\
\hline Race $(\text { Black) })^{* * *}$ & $0.41^{*}$ & 0.19 & $-0.22 *$ & 0.10 \\
\hline \multicolumn{5}{|l|}{ Income $e^{* * *}$} \\
\hline $30000-49000 K$ & -0.17 & 0.17 & -0.07 & 0.18 \\
\hline$>50000$ & 0.04 & 0.26 & 0.00 & 0.09 \\
\hline Missing & -0.05 & 0.34 & 0.22 & 0.14 \\
\hline \multicolumn{5}{|l|}{ Education*** } \\
\hline High school & $0.71^{*}$ & 0.29 & -0.08 & 0.15 \\
\hline Some college & 0.33 & 0.28 & -0.05 & 0.15 \\
\hline College graduate or greater & -0.26 & 0.34 & -0.14 & 0.18 \\
\hline Marital status (married/living together) ${ }^{* * *}$ & -0.05 & 0.17 & -0.03 & 0.09 \\
\hline Agreement between preferred and perceived level of decisional control & 0.30 & 0.17 & 0.00 & 0.09 \\
\hline Influence of side-effects for decision & $0.37^{* *}$ & 0.08 & -0.03 & 0.04 \\
\hline Optimism & $-0.31^{*}$ & 0.14 & $0.25 * *$ & 0.07 \\
\hline Treatment decision-making self-efficacy & $-0.70 * *$ & 0.19 & $0.46^{* *}$ & 0.10 \\
\hline
\end{tabular}

${ }^{*} P<0.05$.

$* * P<0.001$.

*** Referent groups were White, income less than $<\$ 20000$ per year, less than high school education, single.

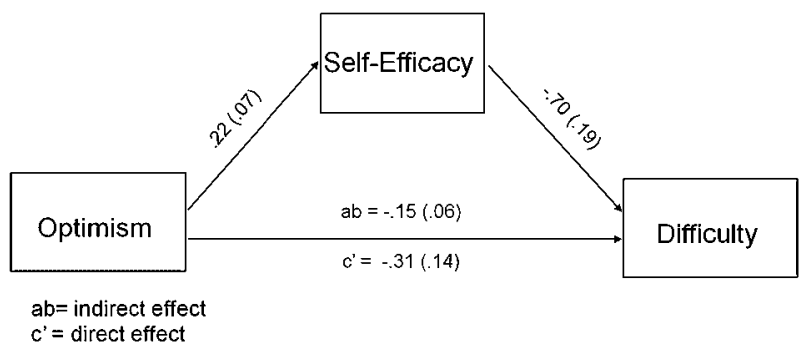

Figure I. Coefficients and associated standard errors for the decision-making difficulty model are presented. In the model, self-efficacy partially mediates the influence of optimism on decision-making difficulty. Although not illustrated, demographic characteristics, influence of side-effects, and agreement between desired and actual level of control were included in the model as control variables

optimism on difficulty with decision-making. The indirect effect associated with self-efficacy was significantly different from zero, even after adjusting for demographic characteristics, influence of side-effects, and agreement between desired and actual level of control $(-0.15,95 \%$ CI: -0.28 , $-0.06, P<0.01$ ) (see Figure 1 for information regarding all pathways tested in the meditational analysis).

\section{Decision-making satisfaction}

Approximately $34 \%$ of the sample reported not being satisfied with the decision-making process, that is, their mean responses on the satisfaction items indicated that they either disagreed or strongly disagreed with statements about being satisfied with the decision-making process. For descriptive purposes, Table 2 contains bivariate relationships between the predictor variables, covariates, and decision-making satisfaction.

Results of the hierarchical multiple regression analysis revealed the relative importance of the different predictor variables for explaining variability in decision-making satisfaction. Demographic characteristics (race, income, education, and marital status) were entered in the first block. This step was not significant $(F(8,116)=0.86$, $P=0.55)$. Next, we entered agreement between preferred and perceived level of decisional control. It did not contribute significantly to the model $\left(R^{2} \Delta=0.00 ; F(1,115)=0.86, P=0.35\right)$. Influence of side-effects was entered next and also did not contribute significantly to the model $\left(R^{2} \Delta=0.01\right.$; $F(1,114)=1.75, P=0.19)$. Next, optimism was added to the model, explaining $14 \%$ of the variability in decision-making satisfaction $\left(R^{2} \Delta=0.14 ; F(1,113)=20.19, P<0.001\right)$. Finally, treatment decision-making self-efficacy accounted for an additional $12 \%$ of the variability in satisfaction $\quad\left(R^{2} \Delta=0.12 ; \quad F(1, \quad 112)=21.29\right.$, $P<0.001)$.

Table 4 contains parameter estimates for the final multiple regression model for decision-making satisfaction. Self-efficacy and optimism were positively associated with decision-making satisfaction $(B=0.46, P<0.001$ and $B=0.25, P<0.001$, respectively). When all the variables were included in the equation, being Black was associated with reporting less satisfaction with the decision-making process $(B=-0.22, P<0.05)$. Again, the effect of race was attributable to a suppressor effect and is discussed in the Discussion section. 


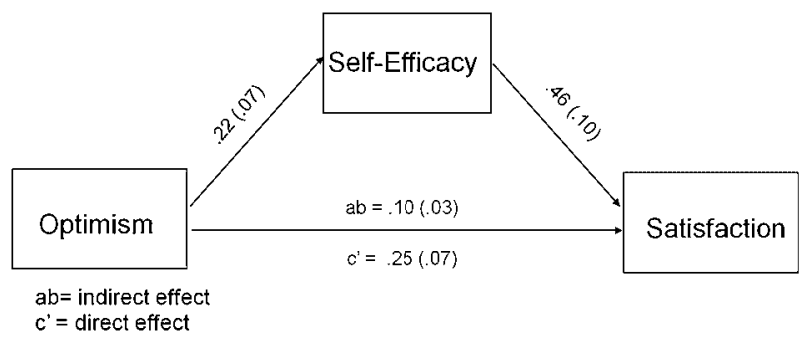

Figure 2. Coefficients and associated standard errors for the decision-making satisfaction model are presented. In the model, self-efficacy partially mediates the influence of optimism on decision-making difficulty. Although not illustrated, demographic characteristics, influence of side-effects, and agreement between desired and actual level of control were included in the model as control variables

\section{Mediational analyses}

The addition of treatment decision-making selfefficacy to the decision-making satisfaction model resulted in a $28.9 \%$ reduction in the effect of dispositional optimism on satisfaction with decision-making. A formal test for mediation revealed that the indirect effect associated with self-efficacy was significantly different from zero even after adjusting for demographic characteristics, influence of side-effects, and agreement between desired and actual level of control $(0.10,95 \%$ CI: 0.04 , $0.17, P<0.01$ ) (see Figure 2 for information on all pathways tested in the meditational analysis).

\section{Difficulty and satisfaction distinct outcomes}

As would be expected, treatment decision-making satisfaction and difficulty significantly co-varied $(r=-0.42, P<0.001)$. One might question whether optimism and self-efficacy predicted both difficulty and satisfaction, or whether they were simply accounting for variability that was common to the two outcome variables. We tested whether including the alternate outcome variable as a covariate (i.e. difficulty was included as a covariate in the satisfaction model) altered the results of the final, fully adjusted multiple regression models. Inclusion of treatment decision-making satisfaction as a covariate in the difficulty model rendered influence of side-effects non-significant. All other previously significant predictor variables remained significant. When treatment decision difficulty was added to the fully adjusted satisfaction model, all of the originally significant predictors remained significant with the exception of race.

\section{Discussion}

This study examined the relationship between dispositional optimism/pessimism or the generalized tendency to expect positive or negative outcomes in important domains of life, self-efficacy, or confidence in making the $\mathrm{PCa}$ treatment decision and
PCa patients' treatment decision-making difficulty and satisfaction [18]. As predicted, dispositional optimism and treatment decision-making self-efficacy predicted both treatment decision-making satisfaction and difficulty, with self-efficacy partially mediating the effects of optimism on the two outcomes. These results were found after controlling the effects of race, income, education, marital status, agreement between patients' preferred and perceived level of decisional control, and self-reported influence of side-effects on their decision.

This study contributes to a growing body of literature that attests to the importance of optimism to psychological and health-related outcomes [18,38]. Furthermore, along with previous studies that have found that a person's level of optimism influences his or her engagement in the cancer treatment decision-making process and treatment decisional uncertainty; results of the present study demonstrate the importance of optimism in predicting people's ability to cope with cancer treatment decision-making [24]. To our knowledge, the present study is the first to demonstrate that treatment decision-making self-efficacy partially mediates the effects of optimism on treatment decision-making and provides evidence of the relative importance of optimism and self-efficacy for treatment decisionmaking satisfaction and difficulty. In combination, the two factors accounted for $15 \%$ of the sample's variability in treatment decision-making difficulty and $26 \%$ of the variability in treatment decisionmaking satisfaction. Evidence suggests that under stressful circumstances, such as making a lifechanging cancer treatment decision, optimistic individuals have a more robust sense of their capacity to meet the challenge and that this sense of self-efficacy is partly responsible for the protective effects of optimism on treatment decision-making satisfaction and difficulty.

Of note, in contrast to previous research with breast cancer patients, agreement between preferred and perceived (actual) levels of decisional control did not predict to either decision-making satisfaction or difficulty [30]. This was the case despite the fact that the rate of agreement between preferred and perceived decisional control (responses were concordant in $67 \%$ of patients) was similar to the median level of agreement $(60 \%)$ reported for 22 studies reviewed by Kiesler and Auerbach in which both preferred and perceived decisional control were assessed [39].

In the multivariate models, but not the bivariate models, being Black was associated with reporting greater treatment decision-making difficulty and less satisfaction. Blacks scored significantly higher on optimism than Whites $t(123)=2.150, P=0.033$ and race emerged as a predictor of perceptions of the decision only when controlling for patients' optimism. The race effect was attributable only to those patients who scored below the median on 
optimism. Black patients scoring below the median on optimism reported more difficulty in making the decision $(t(88)=2.063, P=0.042)$ and marginally less satisfaction with the decision $(t(89)=1.78$, $P=0.079)$ than Whites scoring below the median on optimism; among patients scoring above the median there were no Black-White differences on measures of treatment difficulty or satisfaction.

\section{Strengths, limitations, and future directions}

Participants in the study were a convenience sample of Black and White patients recruited from two Midwestern medical centers. Future research should employ a larger, geographically, and racially diverse sample in order to test the generalizability of the present results and identify sociodemographic groups that may be at risk for treatment-making difficulty or dissatisfaction

Patients completed the survey after they had made their treatment decision, but prior to treatment. This helped avoid response contamination by patients' treatment experiences. Although this was the most appropriate window for assessing treatment decision-making satisfaction and difficulty, ideally we would have assessed treatment decision-making self-efficacy before patients had made their treatment decisions in order to directly test the causal relationship between self-efficacy appraisals and treatment decision-making experiences. We do know, however, that extensive previous research has demonstrated that selfefficacy appraisals causally influence behavior [40]. Similarly, it may have been advantageous to have assessed preferred level of decisional control before patients consulted with physicians regarding treatment options and made their decision, as these experiences could have contaminated patients' responses, or patients may have had difficulty distinguishing between the items used to assess preferred and actual decisional control. The latter may be the lesser of the two concerns as a significant proportion $(33 \%)$ of patients responded to the items differently, suggesting that they had been able to distinguish between them.

The major challenge for future research in this area will be to develop interventions to help reduce $\mathrm{PCa}$ treatment decision-making difficulty. The first challenge is to identify those at risk. A face-valid, efficient method of identifying those with greater likelihood of having difficulty making the decision may be to gauge patients' decision-making selfefficacy by asking how confident they are in their ability to make the decision.

Previous efforts to improve provision of information about PCa and PCa treatment to patients and their family members, and help patients align their treatment decision with their preferences and values have involved the development and use of decision aids [41]. Medical decision-aids also have the potential to reduce the psychological burden of the cancer treatment decision. Some have shown to increase decision-making self-efficacy, increase decision-making participation, satisfaction with the decision-making process and decrease decisional conflict [42]. With a few exceptions, however, decision-aids have not been designed with the express intent of increasing decision-making selfefficacy [43]. Increasing perceptions of self-efficacy, or confidence in one's ability to accomplishing challenging goals has repeatedly proven a valuable component of interventions to increase performance and coping under stressful circumstances, including making difficult decisions $[44,45]$. Given the importance of decision-making self-efficacy to decision-making difficulty and satisfaction, future efforts might incorporate or augment information and exercises designed to boost decision-making selfefficacy. The design of these interventions should draw on basic research that has identified factors that influence self-efficacy perceptions, including previous successes, observing successes by comparable others, somatic and affective information believed to be related to the challenge at hand, persuasive information concerning one's capacity for success, enduring beliefs about the self, and perceived complexity of the challenge [46]. Strategies to enhance decision-making self-efficacy might include the following: (1) One might provide vicarious mastery experiences to patients by describing patient anecdotes that model successful decisionmaking strategies and outcomes. (2) One might provide information that normalizes treatment decision-making anxiety to prevent these cues from being interpreted as signs of difficulty or uncertainty. (3) One might outline goals that represent incremental steps toward making the final decision. When a task is broken into smaller steps, success with incremental goals can boost self-efficacy [47]. (4) Providers may be able to help identify barriers such as low health literacy or family conflict that would result in early decision-making failures or anxiety and erosion of self-confidence.

In sum, the present study demonstrates that patients' personality can play a significant role in the cancer treatment decision-making process. Both optimism and self-efficacy for making the treatment decision were significant predictors of decision-making satisfaction and difficulty. These findings provide a rationale for developing decision-aids or similar interventions that will increase decision-making self-efficacy in patients at risk for decision-making difficulty and, or, low decisionmaking satisfaction.

\section{Acknowledgements}

This project was supported by the Michigan Center for Urban African American Aging Research (NIA P30AG15281) and NIH/NCI University of Michigan 
Cancer Center Prostate SPORE. Dr. Orom was supported by an AHRQ training grant (AHRQ HS013819); Dr. Underwood was supported by a Robert Wood Johnson Harold Amos Medical Faculty Development Award.

\section{References}

1. Jemal A, Siegel R, Ward E et al. Cancer statistics, 2008. CA Cancer J Clin 2008;58:71-96.

2. Yan Y, Carvalhal GF, Catalona WJ et al. Primary treatment choices for men with clinically localized prostate carcinoma detected by screening. Cancer 2000;88:1122-1130.

3. Peschel RE, Colberg JW, Peschel RE et al. Surgery, brachytherapy, and external-beam radiotherapy for early prostate cancer. Lancet Oncol 2003;4:233-241.

4. Klotz L. Active surveillance with selective delayed intervention is the way to manage 'good-risk' prostate cancer. Nat Clin Pract Urol 2005;2:136-142.

5. Post PN, Kil PJ, Hendrikx AJ et al. Comorbidity in patients with prostate cancer and its relevance to treatment choice. Br J Urol Int 1999;84:652-656.

6. Thompson I, Thrasher JB, Aus G et al. Guideline for the management of clinically localized prostate cancer: 2007 update. J Urol 2007;177:2106-2131.

7. Jani AB, Hellman S. Early prostate cancer: clinical decision-making. Lancet 2003;361:1045-1053.

8. Kramer KM, Bennett CL, Pickard AS et al. Patient preferences in prostate cancer: a clinician's guide to understanding health utilities. Clin Prostate Cancer 2005;4:15-23.

9. Davison BJ, Parker PA, Goldenberg SL. Patients' preferences for communicating a prostate cancer diagnosis and participating in medical decision-making. $\mathrm{Br} J$ Urol Int 2004;93:47-51.

10. Pierce PF. Deciding on breast cancer treatment: a description of decision behavior. Nurs Res 1993;42: 22-28.

11. Gwede CK, Pow-Sang J, Seigne $\mathrm{J}$ et al. Treatment decision-making strategies and influences in patients with localized prostate carcinoma. Cancer 2005;104: $1381-1390$

12. Griggs JJ, Sorbero ME, Mallinger JB et al. Vitality, mental health, and satisfaction with information after breast cancer. Patient Educ Couns 2007;66:58-66.

13. Lam WWT, Chan M, Ka HW et al. Treatment decision difficulties and post-operative distress predict persistence of psychological morbidity in Chinese women following breast cancer surgery. Psycho-Oncology 2007;16:904-912.

14. Cervone D. The architecture of personality. Psychol Rev 2004;111:183-204.

15. Allport GW. Personality: A Psychological Interpretation. Holt: New York, 1937.

16. Cervone D, Orom H, Artistico D et al. Using a knowledge-and-appraisal model of personality architecture to understand consistency and variability in smokers' self-efficacy appraisals in high-risk situations. Psychol Addic Behav 2007;21:44-54.

17. Cervone D, Caldwell TL, Fiori $\mathrm{M}$ et al. What underlies appraisals? Experimentally testing a knowledge-andappraisal model of personality architecture among smokers contemplating high-risk situations. J Pers, 2008. In press.

18. Scheier ME, Carver CS. Dispositional optimism and physical well-being: the influence of generalized outcome expectancies on health. J Pers 1987;55:169-210.

19. Deimling GT, Bowman KF, Sterns S et al. Cancerrelated health worries and psychological distress among older adult, long-term cancer survivors. Psycho-Oncology 2006; 15:306-320.

20. Carver CS, Pozo-Kaderman C, Harris SD et al. Optimism versus pessimism predicts the quality of women's adjustment to early stage breast cancer. Cancer 1994;73:1213-1220.

21. Friedman LC, Kalidas M, Elledge R et al. Optimism, social support and psychosocial functioning among women with breast cancer. Psycho-Oncology 2006;15: 595-603.

22. Harper FWK, Schmidt JE, Beacham AO et al. The role of social cognitive processing theory and optimism in positive psychosocial and physical behavior change after cancer diagnosis and treatment. Psycho-Oncology 2007; 16:79-91.

23. Carver CS, Scheier MF, Weintraub JK. Assessing coping strategies: a theoretically based approach. J Pers Soc Psychol 1989;56:267-283.

24. Wong F, Stewart DE, Dancey J et al. Men with prostate cancer: influence of psychological factors on informational needs and decision making. J Psychosom Res 2000;49:13-19.

25. Steginga SK, Occhipinti S. Dispositional optimism as a predictor of men's decision-related distress after localized prostate cancer. Health Psychol 2006;25: 135-143.

26. Bandura A. Self-efficacy: toward a unifying theory of behavioral change. Psychol Rev 1977;84:191-215.

27. Bandura A. Self-Efficacy: The Exercise of Control. Freeman: New York, 1997.

28. Wood RE, Bandura A. Impact of conceptions of ability on self-regulatory mechanisms and complex decision making. J Pers Soc Psychol 1989;56: 407-415.

29. Bandura A, Jourden FJ. Self-regulatory mechanisms governing the impact of social comparison on complex decision making. J Pers Soc Psychol 1991;60: 941-951.

30. Lantz PM, Janz NK, Fagerlin A et al. Satisfaction with surgery outcomes and the decision process in a population-based sample of women with breast cancer.[see comment]. Health Serv Res 2005;40(3): 745-767.

31. Scheier MF, Carver CS, Bridges MW. Distinguishing optimism from neuroticism (and trait anxiety, selfmastery, and self-esteem): a re-evaluation of the Life Orientation Test. J Pers Soc Psychol 1994;67: 1063-1078

32. Janz NK, Wren PA, Copeland LA et al. Patientphysician concordance: preferences, perceptions, and factors influencing the breast cancer surgical decision. $J$ Clin Oncol 2004;22:3091-3098.

33. Maly RC, Umezawa Y, Leake B et al. Determinants of participation in treatment decision-making by older breast cancer patients. Breast Cancer Res Treat 2004; 85:201-209.

34. Holmes-Rovner M, Kroll J, Schmitt $\mathrm{N}$ et al. Patient satisfaction with health care decisions: The Satisfaction with Decision Scale. Med Decis Making 1996;16:58-64.

35. Degner LF, Sloan JA. Decision making during serious illness: what role do patients really want to play? J Clin Epidemiol 1992;45:941-950.

36. Preacher KJ, Hayes AF. Asymptotic and resampling strategies for assessing and comparing indirect effects in multiple mediator models. Behavior Research Methods 2008;40:879-891.

37. Cohen J, Cohen P, West SG et al. Applied Multiple Regression/Correlation Analysis for the Behavioral Sciences (3rd edn). Lawrence Erlbaum Associates: Mahweh, NJ, 2002. 
38. Rasmussen HN, Wrosch C, Scheier MF et al. Selfregulation processes and health: the importance of optimism and goal adjustment. J Pers 2006;74: 1721-1747.

39. Kiesler DJ, Auerbach SM. Optimal matches of patient preferences for information, decision-making and interpersonal behavior: evidence, models and interventions. Patient Educ Couns 2006;61:319-341.

40. Bandura A, Locke EA. Negative self-efficacy and goal effects revisited. J Appl Psychol 2003;88:87-99.

41. Neuman HB, Charlson ME, Temple LK. Is there a role for decision aids in cancer-related decisions? Crit Rev Oncol Hematol 2007;62:240-250.

42. Whelan T, Levine M, Willan A et al. Effect of a decision aid on knowledge and treatment decision making for breast cancer surgery: a randomized trial. $\mathrm{J} \mathrm{Am} \mathrm{Med}$ Assoc 2004;292:435-441.
43. Davison BJ, Degner L. Empowerment of men newly diagnosed with prostate cancer. Cancer Nurs 1997;20: 187-196.

44. Fukuyama MA, Probert BS, Neimeyer GJ et al. Effects of DISCOVER on career self-efficacy and decision making of undergraduates. Career Dev $Q$ 1988;37:56-62.

45. Sullivan KR, Mahalik JR. Increasing career self-efficacy for women: evaluating a group intervention. J Couns Dev 2000;78:54-62.

46. Mangos PM, Steele-Johnson D. The role of subjective task complexity in goal orientation, self-efficacy, and performance relations. Hum Perform 2001;14: 169-186.

47. Bandura A, Schunk DH. Cultivating competence, selfefficacy and intrinsic interest through proximal selfmotivation. J Pers Soc Psychol 1981;41:586-598. 